\title{
Production of bioethanol from wheat straw via optimization of co-culture conditions of Bacillus licheniformis and Saccharomyces cerevisiae
}

\author{
Shweta Sharma \\ Lovely Professional University \\ Paras Kumar Jha \\ Lovely Professional University \\ Amit Panwar ( $\Delta$ amitpanwar6005@gmail.com ) \\ Lovely Professional University
}

\section{Research Article}

Keywords: Bioethanol, Co-culturing, Wheat straw, Bacillus licheniformis, Saccharomyces cerevisiae

Posted Date: July 16th, 2021

DOI: https://doi.org/10.21203/rs.3.rs-714388/v1

License: (c) (i) This work is licensed under a Creative Commons Attribution 4.0 International License.

Read Full License 


\section{Abstract}

Bioethanol production has been a challenge for the researchers to enhance the bioethanol yield. In this study, we are reporting an efficient novel method to produce bioethanol. The process comprises co-culture technique to produce bioethanol from wheat straw by co-culturing Bacillus licheniformis and Saccharomyces cerevisiae. Simultaneous saccharification and fermentation allows wheat straw hydrolysis by cellulase enzyme produced by Bacillus licheniformis and conversion of produced reducing sugar into ethanol by Saccharomyces cerevisiae. Pre-treatment of wheat straw and optimization of coculturing parameters like, time, $\mathrm{pH}$, substrate concentrations and nitrogen source concentrations gave a net yield of $5.67 \% \mathrm{v} / \mathrm{v}$ bioethanol. Scale up of optimised media to fermenter has resulted in a significant enhancement of bioethanol production to $18.64 \%(\mathrm{v} / \mathrm{v})$.

\section{Introduction}

In the present state, world's requirement for fuel is increasing at high rate in contrast to the fossil fuels [1]. Production of fuel from waste products have the potential to provide a solution for cost effectiveness and sustainability. Ethanol is an eco-friendly fuel in contrast to other substrates which causes green-house gas emissions when employed as fuel [2]. It is now being used as an additive to biodiesel and have increased the biodiesel's energy yield for automobile industry [3]. And is being employed as fuel for many industrial applications in many countries [4]. In pharmaceutical industry, ethanol is a major solvent for the synthesis of drugs and their derivatives [5]. Due to increase in demand of ethanol and high cost of production using traditional substrates like molasses and malt, ethanol produced is insufficient and expensive. There is need of a cost effective and an abundant source of ethanol [6]. A process is required which can simply convert substrate into ethanol with less complexity and cost effectiveness.

Production of ethanol from waste lignocellulosic agricultural products would be able to provide an opportunity to replace the conventional expensive methods of production [7]. As lignocellulosic substrate is one of the most abundant, renewable, and low-cost substrates for ethanol production. Wheat straw is excessively available in nature as an agricultural waste and contains $35-45 \%$ cellulose [8]. However, it is required to give a pre-treatment to the raw wheat straw to facilitate hydrolysis as well as ethanol production. It has been observed that pre- treatment of lignocellulosic substrate has increased the availability of the substrate for glucose production and increased the ethanol yield [9]. Various pretreatment methods have been employed by the researchers involving physical, chemical, and enzymatic pre-treatments [10]. Bioethanol production via enzymatic pre-treatment with cellulolytic enzymes followed by microbial fermentation is an efficient method. However, enzymatic methods are expensive and are substrate specific [11]. Physical and chemical pre-treatments of raw cellulose sources have been optimized and is cost-effective [10].

After pre-treatment of the wheat-straw, cellulose fibres have been observed to become more prone to microbial hydrolytic degradation in comparison to raw substrate [12]. Microbial hydrolytic degradation involves the release of cellulolytic enzymes by the microbes to produce monosaccharides. In the next 
step for bioethanol production, monosaccharide rich medium is inoculated with the ethanol producing microbes. Several bacterial and yeast strains have been employed and optimized to carry out the stepwise production of bio-ethanol production. To decrease the number of steps involved in bioethanol production, researchers have developed genetically engineered strains which can both degrade as well as convert degraded cellulose to ethanol [13]. In addition, immobilisation is another technique employed to produce ethanol where one strain is immobilised for the degradation of lignocellulose substrate and microbes are added in mobile phase for ethanol production [14]. However, cost for using two different systems for separate enzyme production and the instability of genetically engineered strains is major problem being faced by the industry. Co-culture is a technique which has been used by researchers where combination of two microbes have been employed to carry out the stepwise conversion in a controlled way [15]. Simultaneous saccharification and fermentation has been explored by the researchers by employing various combinations of microorganisms and enzymes. SSF of alkali treated paddy field was carried out xxxxxx and coworkers by using 2g/l commercial enzymes (Cellulase T "Amano 4" : Cellulase "Onozuka 3S": Pectinase G "Amano") and $1 \mathrm{M}$ of circinelloide at $10 \%$ solid biomass loading at $28^{\circ} \mathrm{C}$ and $\mathrm{pH}$ of 5.5 and

Have produced $30.5 \mathrm{~g} / \mathrm{l}$ of ethanol in 36 hours [16]. However, employment of commercial enzymes would affect the cost effectiveness of the ethanol production. Also ,microbes have been employed by the researchers to produce cellulases for the hydrolysis of complex cellulose substrates. In case of microbes, the major challenge is the selection of microbial strain due to difference in the working temperature and $\mathrm{pH}$ of the hydrolytic enzymes and the fermenting strains. Most common fermenting strains employed is Saccharomyces cerevisiae, which ferments at $30-37^{\circ} \mathrm{C}$ and $6-7 \mathrm{pH}$. Microbe like fungal strains have been utilized for the hydrolysis of complex cellulose substrates. However, the optimum temperature and $\mathrm{Ph}$ for the activity of cellulases are $40-60^{\circ} \mathrm{C}$ and $\mathrm{pH} 4.8-5.5$ [17]. B. licheniformis has been studied extensively for its potential for producing cellulases to degrade complex cellulose substrates $[18,19]$.

In this study, co-culture technique is used to produce ethanol in one system to produce ethanol from wheat straw instantaneously. Process of ethanol production was optimized by varying the fermentation time, $\mathrm{pH}$, substrate concentration and nitrogen source concentration to enhance the yield of bioethanol. Bacillus licheniformis was employed for the hydrolytic degradation of lignocelluloses and Saccharomyces cerevisiae for bioethanol production for simultaneous saccharification and fermentation (SSF). Simultaneous saccharification and fermentation took place in co-culture, where Bacillus licheniformis and Saccharomyces cerevisiae grow together but Saccharomyces cerevisiae's growth totally is dependent on glucose produced by the Bacillus licheniformis. The process was further scaled up to bioreactor, where SSF has resulted in the production of $18.64 \% \mathrm{v} / \mathrm{v}$ bioethanol under optimized conditions.

\section{Material And Methods}

\subsection{Materials}


Soluble starch, sodium thiosulphate, phenol and sulphuric acid were purchased from Lobachemie Pvt. Ltd. Wheat straw was procured from local farmer of PBW621 variety. Potassium dichromate and peptone was purchased from central drug house, India. Yeast extract, agar and ammonium nitrate were purchased from Titan Pvt. Ltd, India. Dextrose, 3,5-dinitrosalicylic acid and sodium meta bisulphite were purchased from Molychem Pvt. Ltd. and potassium iodide and potassium hydroxide was purchased from Thomas Baker (chemicals) Pvt. Ltd., India. Rochelle salt was obtained from Qualikems Pvt. Ltd., India. Saccharomyces cerevisiae (MTCC No. 464) and Bacillus licheniformis (MTCC No. 429) was procured from IMTECH, Chandigarh.

\subsection{Preparation of wheat straw media}

The PBW621 variety of wheat straw was dried in hot air oven and grounded to proper size using a blender. $5 \mathrm{mg} / \mathrm{ml}$ of wheat straw and $2.5 \mathrm{mg} / \mathrm{ml}$ of ammonium nitrate was added in $100 \mathrm{ml}$ of double distilled water and was autoclaved at $15 \mathrm{Psi}$ at $121^{\circ} \mathrm{C}$.

\subsection{Alkali pretreatment of wheat straw media}

Pretreatment of wheat straw media was carried out by treating wheat straw media with $1 \% \mathrm{w} / \mathrm{v}$ potassium hydroxide and followed by 24 hours incubation at room temperature. Further the alkali treated media was autoclaved at $15 \mathrm{psi}$ and $121^{\circ} \mathrm{C}[20,21]$.

\subsection{Glucose/ Reducing sugars estimation by DNS (Dinitrosalicylic acid) method}

Reducing sugars were quantified as per earlier reported method by Miller [22].1 ml of supernatant was taken in a test tube and $3 \mathrm{ml} \mathrm{DNS}$ reagent was added to it. The tubes were heated in a water bath at $80^{\circ} \mathrm{C}$ for 20 minutes. Further, the tubes were cooled to room temperature and optical density (O.D) was measured at $540 \mathrm{~nm}$ by using UV spectrophotometer (Sistronics). A standard curve was prepared by using $1 \mathrm{mg} / \mathrm{ml}$ glucose solution for the estimation of reduced sugars.

\subsection{Simultaneous saccharification and fermentation (SSF)}

In a typical reaction, the nascent and pretreated wheat straw media was inoculated with Bacillus licheniformis $\left(10^{8} \mathrm{CFU} / \mathrm{ml}\right)$ and incubated in an incubator shaker at $30^{\circ} \mathrm{C}$ for 48 hours. Further, the media was co-cultured with Saccharomyces cerevisiae $\left(10^{8} \mathrm{CFU} / \mathrm{ml}\right)$ and incubated in an incubator shaker at $30^{\circ} \mathrm{C}$ for 120 hours. The effect of different parameters on production of ethanol was optimized by changing the co-inoculation time $(24,48,72$ hours), substrate concentration $(2.5,5.0,7.5$ and 10.0 $\mathrm{mg} / \mathrm{ml}), \mathrm{pH}$ of media $(\mathrm{pH} 5,6,7,8)$ and concentration of nitrogen source $(0.03,0.06,0.09$ and $0.12 \mathrm{M})$. Samples were taken for ethanol quantification at every 24 hours interval from each flask using potassium dichromate redox titration method and gas chromatography [23]. The best optimized reaction condition was scaled up from $100 \mathrm{ml}$ to 1.5 liters pre-sterilized fermenter. The fermenter conditions were set to $30^{\circ} \mathrm{C}$ and agitation speed at $121 \mathrm{rpm}$ [24]. Aeration was given for cell growth followed by anaerobic condition as per earlier reported method [25]. 


\subsection{Scale up of SSF}

The BIOAGE fermenter of 3 litres capacity was filled with 2 litres distilled water and autoclaved. Further, autoclaving along with the fermentation medium was done after setting the $\mathrm{pH}$ to 7 and media was allowed to cool down to room temperature. Bacillus licheniformis was inoculated in 1.5 litres of fermentation medium with $10^{8} \mathrm{CFU} / \mathrm{ml}$. The fermenter conditions were set to $30^{\circ} \mathrm{C}$ and agitation speed was set at $121 \mathrm{rpm}$. After $72 \mathrm{hrs}$ Saccharomyces cerevisiae was inoculated. Aeration was given for cell growth followed by anaerobic condition at $10^{8} \mathrm{CFU} / \mathrm{ml}$ [14]. For determining the concentration of ethanol sample was centrifuged and supernatant was collected separately. And sample was analysed by GC [15].

\subsection{Ethanol estimation by potassium dichromate method}

$1 \mathrm{ml}$ of the fermented broth was centrifuged and dispersed into round bottom flasks containing $30 \mathrm{ml}$ of distilled water fixed to a distillation column cooled down by cold tap water. A conical flask containing 25 $\mathrm{ml}$ of potassium dichromate solution (33.768 $\mathrm{g}$ of $\mathrm{K}_{2} \mathrm{Cr}_{2} \mathrm{O}_{7}$ dissolved in $400 \mathrm{ml}$ of distilled water with 325 $\mathrm{ml}$ of sulphuric acid and volume raised to 1 litre) was fixed to the other end of the distillation column to collect the distillate. A heating mantle with the temperature adjusted to $78^{\circ} \mathrm{C}$ was used to heat the round bottomed flask. $20 \mathrm{ml}$ of distillate was collected in each sample and the flasks were kept in a water bath maintained at $62.5^{\circ} \mathrm{C}$ for 20 minutes. The flasks were cooled to room temperature and $30 \mathrm{ml}$ distilled water was added to it to make the final volume $50 \mathrm{ml}$. this sample is now used for measuring the optical density at $600 \mathrm{~nm}$ using UV spectrophotometer. A standard curve was prepared under similar set of conditions by using standard solution of ethanol containing 2 to $12 \%(\mathrm{v} / \mathrm{v})$ ethanol in distilled water. The percentage ethanol concentration of ethanol produced was obtained by comparing its optical density with the standard ethanol density curve.

\subsection{Bioethanol estimation by Gas chromatography (GC) method}

Ethanol present in the fermentation broth was quantified by gas chromatography method. Agilent 6890 gas chromatograph equipped with Flame lonization Detector (FID) was employed for the separation and quantification of ethanol. A Zebron column was fitted into the instrument to provide on column injection. The detector and injector temperature were maintained at $260^{\circ} \mathrm{C}$. The gas chromatograph was connected to an integrator and computer system to determine area of ethanol and internal standard peak.

Formula to find ethanol\% v/v from GC data analysis:-

Response factor $=$ Peak area $/$ sample amount

Amount of analyte $=$ peak area $/$ response factor

$w / v$ value is then converted to $\% v / v$

\section{Results And Discussion}


For ethanol production, wheat straw media was prepared and pre-treated with alkali to facilitate the hydrolysis and fermentation process as per earlier reported method as shown in Fig. 1. The steam and alkali pre-treatment of wheat straw demonstrated an increase in glucose production from $0.184 \mathrm{mg} / \mathrm{ml}$ to $0.223 \mathrm{mg} / \mathrm{ml}$ compared to untreated wheat straw after 24 hours of co-culturing (Fig S1). Alkali pretreatment has been observed to increase the degradation of hemicellulose and lignin. Increase in degradation is due to the removal of acetate group from the hemicellulose, increasing the access of hydrolytic enzymes to cellulose [26]. In addition to this, alkali addition results in lignin solubilization which also enhance the enzyme susceptibility [27]. Matrix of cellulose and lignin are held together by hemicellulose chains in a lignocellulosic complex. During pre-treatment, the lignin-cellulose matrix breaks down and reduce the crystallinity by enhancing the proportion of the amorphous phase [28].

After pre-treatment of the wheat straw media, the media was inoculated with $B$. licheniformis to produce reducing sugars by enzymatic hydrolysis. Later, media was inoculated with $S$. cerevisiae for co-culturing to produce bioethanol via SSF. Time point for the inoculation of $S$. cerevisiae for co-culturing was optimized by inoculating the S. cerevisiae at 0 th hour, 24th hour and 48th hour after the inoculation of $B$. licheniformis. It was observed that inoculation at 48th hour has produced highest bioethanol in comparison to other time points (shown in figure S2). Owing to sufficient time provided for $B$. licheniformis to produce reducing sugars helps in enhancing the ethanol production. Enzymatic hydrolysis plays an important role in enhancing the production of reducing sugars and would further increase the ethanol production. For the better enzymatic activity, environmental conditions play an important role. $\mathrm{pH}$ and temperature are the most important factors and have been optimized to improve enzymatic activity as well as growth of micro-organisms. In this study, $\mathrm{pH}$ was optimized for co-culturing by performing SSF at different $\mathrm{pH}(5,6,7$ and 8$)$ at $37^{\circ} \mathrm{C}$. in Fig. 2 , higher production of reducing sugars as well as ethanol demonstrates the suitable $\mathrm{pH}$ required for the SSF. The ethanol production was increase from $1.04 \pm 0.15 \%$ to $2.46 \pm 0.18 \% \mathrm{v} / \mathrm{v}$, when the $\mathrm{pH}$ was changed from 5 to 7 after 96 hours of SSF. However, further increase in $\mathrm{pH}$ to 8 has decreased the ethanol production to $2.18 \pm 0.034 \% \mathrm{v} / \mathrm{v}$ (Fig. $2 \mathrm{~A}$ ). In situ analysis of ethanol and glucose was carried out up to 96 hours of SSF as shown in Fig. 2B. Decrease in glucose concentration with increase in ethanol production demonstrated the conversion carried out by $\mathrm{S}$. cerevisiae under anaerobic conditions. Ethanol concentration in wheat straw medium has increased from $₫ 0.55 \% \mathrm{v} / \mathrm{v}$ after 24 hours to $\varangle 2.46 \% \mathrm{v} / \mathrm{v}$ at $\mathrm{pH}$ 7. Gupta et al have also demonstrated that $\mathrm{B}$. licheniformis demonstrated $>90 \%$ cellulase activity at $\mathrm{pH} 7$ in case of water soluble carboxymethylcellulose (CMC) [29].

Substrate concentration in wheat straw medium plays an important role in improving the growth as well as production of enzymes in microbes. To optimize the substrate concentration, 2.5, 5.0, 7.5 and 10.0 $\mathrm{mg} / \mathrm{ml}$ of substrates concentrations were prepared to perform SSF. Ethanol production increases from $\varangle 2.91 \%$ to $4.29 \pm 0.27 \% \mathrm{v} / \mathrm{v}$ ( 96 hours SSF) after increasing substrate concentration from 2.5 to 5.0 $\mathrm{mg} / \mathrm{ml}$ as shown in Fig. 3A. However, further increase in substrate concentration to 7.5 and $10 \mathrm{mg} / \mathrm{ml}$ has decreased the ethanol production to $3.79 \pm 0.014 \%$ and $3.27 \pm 0.007 \% \mathrm{v} / \mathrm{v}$, respectively. Glucose estimation at different substrate concentration demonstrates a decrease in glucose production when the 
substrate concentration was increased from $5 \mathrm{mg} / \mathrm{ml}$ to 7.5 and $10.0 \mathrm{mg} / \mathrm{ml}$ as shown in Fig. 3B. The decrease in ethanol production could be due to catabolite repression that tends to lower the yield of glucose, thereby, lowering the ethanol production [30].

Apart from wheat straw, a nitrogen source was added in the form of ammonium nitrate to prepare wheat straw medium. Nitrogen source is essential to boost up the production of proteins/enzymes required for the intra-cellular processes during the growth and division of the micro-organisms. Ammonium nitrate was used as a nitrogen source for SSF as it has been observed to support higher cellulase synthesis by micro-organisms in comparison to other nitrogen sources [31]. For bioethanol production, nitrogen source was optimized by performing SSF at $0.03,0.06,0.09$ and $0.12 \mathrm{M}$ concentrations of ammonium nitrate in wheat straw medium. Bioethanol production increased from $4 \pm 0.014 \%$ to $5.67 \pm 0.28 \%$, on increasing nitrogen source concentration from $0.03 \mathrm{M}$ to $0.06 \mathrm{M}$ as shown in Fig. 4A. Whereas further increase in nitrogen source concentration has declined the bioethanol production to $4.76 \pm 0.34 \%$ and $3.14 \pm 0.23 \%$ $\mathrm{v} / \mathrm{v}$ for $0.09 \mathrm{M}$ and $0.12 \mathrm{M}$, respectively. Decline in bioethanol production could be due to catabolite repression, which has decreased the cellulase production and have resulted in lower glucose production. Similar behaviour has been reported by Hernandez and coworkers while studying the effect of nitrogen source effect on ethanol production in S. cerevisiae [32].

Optimization of co-culture time, substrate concentration, $\mathrm{pH}$ of wheat straw medium and nitrogen source concentration demonstrated an increase in bioethanol production. For better control over the SSF process and the process parameters, the process was scaled up to 1.5 litre fermenter level to further improve the bioethanol production. SSF process was carried out by employing the optimized parameters in BIO-AGE 3 litres fermenter. Bioethanol produced was characterized through gas chromatography, which demonstrated a sharp increase in ethanol production from $₫ 5.67 \%$ to $\otimes 18.64 \% \mathrm{v} / \mathrm{v}$ (Shown in figure S6). Studies by Mosier et al have demonstrated similar rise in ethanol production after scaling up o fermenter level [21].

\section{Conclusion}

Optimized co-culture conditions for B. licheniformis and $S$. cerevisiae were successfully established to produce bioethanol. The alkaline pre-treatment of wheat straw medium was observed to be a contributing factor along with other factors including $\mathrm{pH}$, substrate concentration and nitrogen source concentration, towards enhancement in the production of bioethanol. The optimization of the given process parameters showed that the highest ethanol production by co-culturing of $B$. licheniformis and $S$. cerevisiae was achieved after 48 hours of co-culturing at a $\mathrm{pH}$ of 7 , with nitrogen source and substrate concentration $0.06 \mathrm{M}$ and $5 \mathrm{mg} / \mathrm{ml}$, respectively. Scale up of the SSF process to fermenter level has resulted in further enhancement of bioethanol production from $5.8 \% \mathrm{v} / \mathrm{v}$ to $18.64 \% \mathrm{v} / \mathrm{v}$.

\section{Declarations}

\section{Acknowledgements}


The financial assistance received from the Lovely Professional University (LPU.), Punjab, India is deeply acknowledged. I would like to extend our thanks to School of Biosciences and Biotechnology, LPU. We are thankful to Allele life sciences (P) Ltd, India for providing the facility of Gas chromatography for characterization.

\section{Data availability}

The datasets generated during and/or analysed during the current study are available from the corresponding author on reasonable request.

\section{References}

1. Rosero F, et al. Effects of passenger load, road grade, and congestion level on real-world fuel consumption and emissions from compressed natural gas and diesel urban buses. Appl Energy. 2021;282:116195.

2. Deshmukh AS, et al. PERFORMANCE ANALYSIS OF ETHANOL BLENDED GASOLINE FUEL IN INTERNAL COMBUSTION SPARK IGNITION ENGINE. International Engineering Journal For Research Development. 2021;6(3):10-0.

3. Venu $\mathrm{H}$, et al. Influence of Al203nano additives in ternary fuel (diesel-biodiesel-ethanol) blends operated in a single cylinder diesel engine: Performance, Combustion and Emission Characteristics. Energy. 2021;215:119091.

4. Demirbas AH, Demirbas I. Importance of rural bioenergy for developing countries. Energy Convers Manag. 2007;48(8):2386-98.

5. Grodowska K, Parczewski A. Organic solvents in the pharmaceutical industry. Acta Poloniae Pharmaceutica. Drug Research, 2010. 67(1).

6. Todhanakasem T, Wu B, Simeon S. Perspectives and new directions for bioprocess optimization using Zymomonas mobilis in the ethanol production. World Journal of Microbiology Biotechnology. 2020;36(8):1-16.

7. Jeffries TW, et al. Genome sequence of the lignocellulose-bioconverting and xylose-fermenting yeast Pichia stipitis. Nature biotechnology. 2007;25(3):319-26.

8. Chen H-Z, Liu Z-H. Multilevel composition fractionation process for high-value utilization of wheat straw cellulose. Biotechnology for biofuels. 2014;7(1):1-12.

9. Saini S, Chandel AK, Sharma KK. Past practices and current trends in the recovery and purification of first generation ethanol: A learning curve for lignocellulosic ethanol. J Clean Prod. 2020;268:122357.

10. Rezania S, et al. Different pretreatment technologies of lignocellulosic biomass for bioethanol production: An overview. Energy. 2020;199:117457.

11. Nawaz A, et al. Pilot Scale Elimination of Phenolic Cellulase Inhibitors From Alkali Pretreated Wheat Straw for Improved Cellulolytic Digestibility to Fermentable Saccharides. Frontiers in Bioengineering Biotechnology. 2021;9:179. 
12. Xu C, et al. Effects of pretreatments on physical and chemical characteristics of wheat straw used as a maintenance-free compressed green roof substrate material. J Clean Prod. 2020;277:123381.

13. Wu M, et al. Simulating extracellular glucose signals enhances xylose metabolism in recombinant Saccharomyces cerevisiae. Microorganisms. 2020;8(1):100.

14. Malik K, et al. Co-fermentation of immobilized yeasts boosted bioethanol production from pretreated cotton stalk lignocellulosic biomass: Long-term investigation. Ind Crops Prod. 2021;159:113122.

15. Rojas-Chamorro J, et al. Improved ethanol production from the slurry of pretreated brewers' spent grain through different co-fermentation strategies. Bioresour Technol. 2020;296:122367.

16. Takano M, Hoshino K. Bioethanol production from rice straw by simultaneous saccharification and fermentation with statistical optimized cellulase cocktail and fermenting fungus. Bioresources Bioprocessing. 2018;5(1):16. DOI:10.1186/s40643-018-0203-y.

17. Walia A, et al. Purification and characterization of cellulase-free low molecular weight endo $\beta-1,4$ xylanase from an alkalophilic Cellulosimicrobium cellulans CKMX1 isolated from mushroom compost. World Journal of Microbiology Biotechnology. 2014;30(10):2597-608. DOI:10.1007/s11274-014-1683-3.

18. Azadian F, et al. Purification and biochemical properties of a thermostable, haloalkaline cellulase from Bacillus licheniformis AMF-07 and its application for hydrolysis of different cellulosic substrates to bioethanol production. Molecular Biology Research Communications. 2016;5(3):143.

19. Zafar A, et al. Cloning, expression, and purification of xylanase gene from Bacillus licheniformis for use in saccharification of plant biomass. Appl Biochem Biotechnol. 2016;178(2):294-311.

20. Hamelinck CN, Van Hooijdonk G, Faaij AP. Ethanol from lignocellulosic biomass: techno-economic performance in short-, middle-and long-term. Biomass bioenergy. 2005;28(4):384-410.

21. Mosier $\mathrm{N}$, et al. Features of promising technologies for pretreatment of lignocellulosic biomass. Bioresour Technol. 2005;96(6):673-86.

22. Miller GL. Use of dinitrosalicylic acid reagent for determination of reducing sugar. Analytical chemistry. 1959;31(3):426-8.

23. Rastogi $\mathrm{G}$, et al. Isolation and characterization of cellulose-degrading bacteria from the deep subsurface of the Homestake gold mine, Lead, South Dakota, USA. Journal of industrial microbiology biotechnology. 2009;36(4):585.

24. Eneojo A, Aliyu S, Bukbuk D. Potentials of wild strain Saccharomyces cerevisiae in ethanol production. American-Eurasian Journal of Scientific Research. 2010;5(3):187-91.

25. Deka D, et al., Enhanced cellulase production from Bacillus subtilis by optimizing physical parameters for bioethanol production. International Scholarly Research Notices, 2013. 2013.

26. Kong F, Engler CR, Soltes EJ. Effects of cell-wall acetate, xylan backbone, and lignin on enzymatic hydrolysis of aspen wood. Appl Biochem Biotechnol. 1992;34(1):23-35.

27. Tong Z, Pullammanappallil P, Teixeira AA. How ethanol is made from cellulosic biomass. EDIS, 2012. 2012(12). 
28. Sánchez ÓJ, Cardona CA. Trends in biotechnological production of fuel ethanol from different feedstocks. Biores Technol. 2008;99(13):5270-95.

DOl:https://doi.org/10.1016/j.biortech.2007.11.013.

29. Gupta M, et al. Enhanced Production of Cellulase from Bacillus licheniformis K-3 with Potential for Saccharification of Rice Straw. Energy Technology. 2015;3(3):216-24.

DOl:https://doi.org/10.1002/ente.201402137.

30. Xiao Z, et al. Effects of sugar inhibition on cellulases and $\beta$-glucosidase during enzymatic hydrolysis of softwood substrates. in Proceedings of the Twenty-Fifth Symposium on Biotechnology for Fuels and Chemicals Held May 4-7, 2003, in Breckenridge, CO. 2004. Springer.

31. Kachlishvili $E$, et al. Effect of nitrogen source on lignocellulolytic enzyme production by white-rot basidiomycetes under solid-state cultivation. World Journal of Microbiology Biotechnology. 2006;22(4):391-7.

32. Hernandez-Orte $P$, et al. The development of varietal aroma from non-floral grapes by yeasts of different genera. Food Chem. 2008;107(3):1064-77.

\section{Figures}


Wheat straw grinding

Preparation of wheat straw medium

Pre-treatment of wheat straw medium

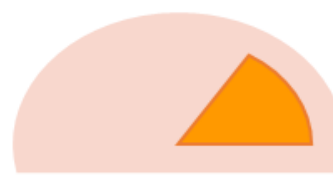

Optimization of wheat straw medium

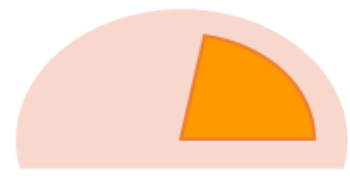

Inoculation of B. licheniformis \& incubation (48 hrs@37º

Inoculation of S. cerevisiae \& incubation (96 hrs@37 C)
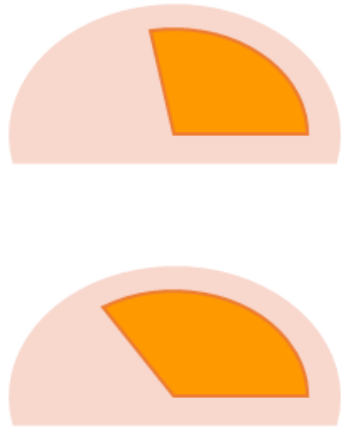

Simultaneous saccharification \& fermentation (SSF)

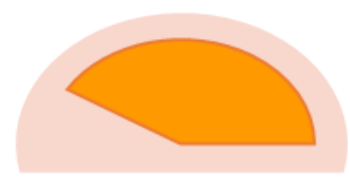

\section{Figure 1}

Schematics to demonstrate the Simultaneous saccharification and fermentation (SSF) for bioethanol production from wheat straw 


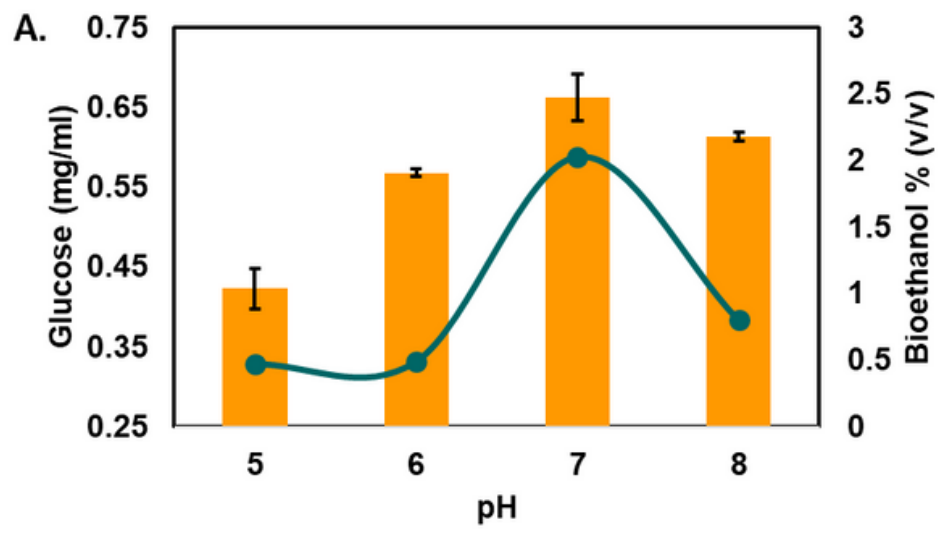

Ethanol@96 hrs - -Glucose@24 hrs

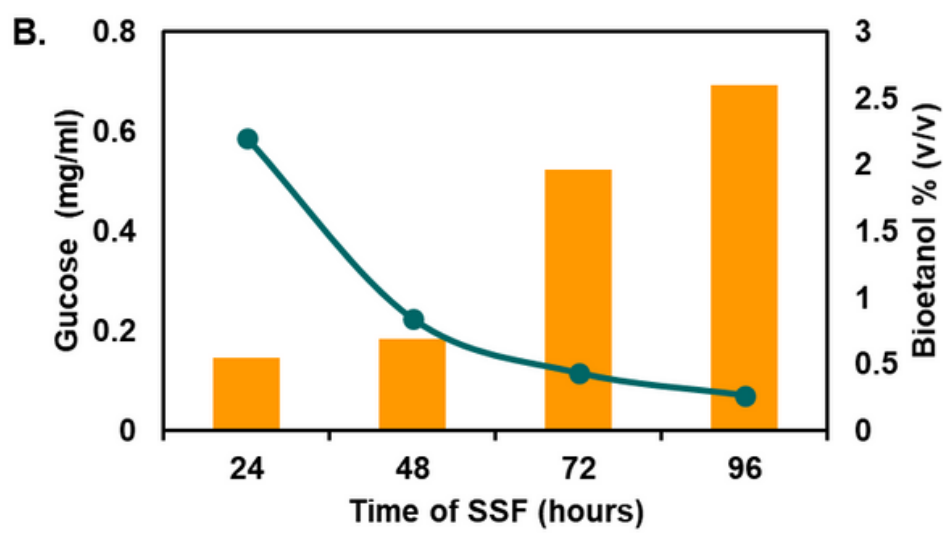

Ethanol $\rightarrow-$ Glucose

Figure 2

Optimization of bioethanol production by varying $\mathrm{pH}$ of the wheat straw medium $(\mathrm{A})$ and in situ analysis of glucose and bioethanol produced during SSF at $\mathrm{pH} 7$

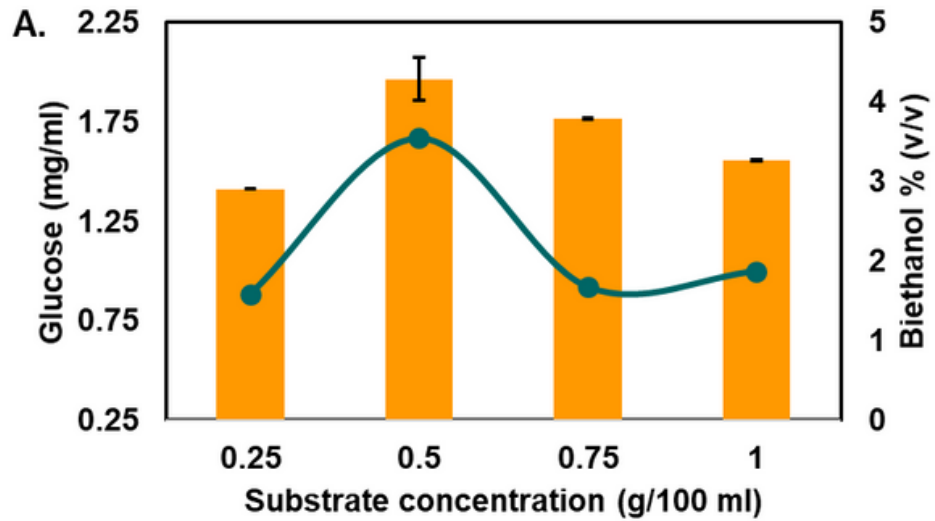

Substrate concentration $(\mathrm{g} / 100 \mathrm{ml})$

Ethanol@96 hrs

-Glucose@24 hrs
B.
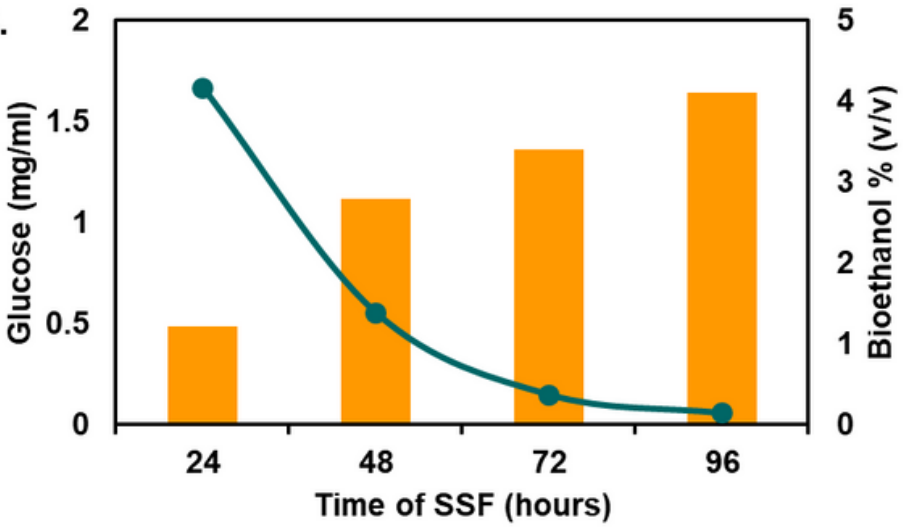

Ethanol $\rightarrow$ Glucose

\section{Figure 3}

(A)optimization of substrate concentration in wheat straw medium for bioethanol production; (B) In situ analysis of glucose and bioethanol during SSF at $0.5 \mathrm{~g} / 100 \mathrm{ml}$ substrate concentration and $\mathrm{pH} 7$.

A.

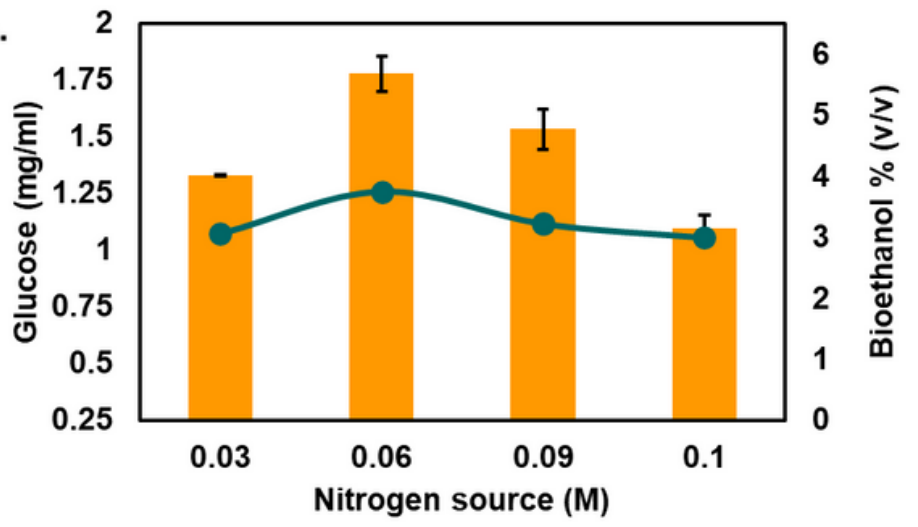

Ethanol@96 hrs
B.

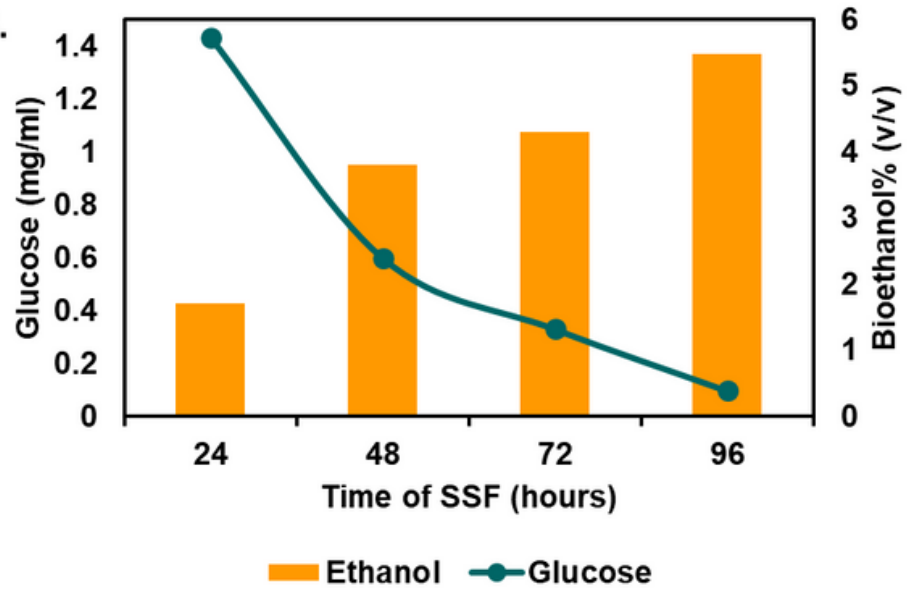


Figure 4

(A) Optimization of nitrogen source concentration in wheat straw medium for bioethanol production; (B) In situ analysis of glucose and bioethanol during SSF at pH 7, $0.06 \mathrm{M}$ nitrogen source.

\section{Supplementary Files}

This is a list of supplementary files associated with this preprint. Click to download.

- Supportinginformation.docx 